\title{
Advanced Insulations for Refrigerator/Freezers: The Potential for New Shell Designs Incorporating Polymer Barrier Construction
}

\author{
Brent T. Griffith and Dariush Arasteh \\ Energy and Environment Division \\ Lawrence Berkeley Laboratory \\ University of California \\ 1 Cyclotron Road \\ Berkeley, California 94720
}

November 1992

This work was funded by the U.S. Environmental Protection Agency, Office of Research and Development under Inter-Agency Agreement No. DW89935253-01-0. Additional funding was provided by Southern California Edison through the California Institute for Energy Efficiency (CIEE), a research unit of the University of California, under Contract No. EXPC-92-02. Publication of research results does not imply CIEE endorsement of or agrecment with these findings, nor that of any CIEE sponsor. Additional funding was provided by the Assistant Secretary for Conservation and Renewable Energy, Office of Building Technologies, Building Systems and Materials Division of the U.S. Department of Energy under Contract No. DE-AC03-76SF00098. 


\section{TABLE OF CONTENTS}

\begin{tabular}{llc}
\hline & LIST OF FIGURES & 1 \\
& LIST OF TABLES & 1 \\
& EXECUTIVE SUMMARY & 2 \\
1.0 & BACKGROUND AND INTRODUCTION & 4 \\
2.0 & ADVANCED INSULATION TECHNOLOGIES & 7 \\
3.0 & THERMAL RESISTANCE ISSUES FOR CONVENTIONAL R/F & 9 \\
& DESIGN & \\
4.0 & THREE-DIMENSIONAL HEAT TRANSFER MODELING OF A & 11 \\
& SIMPLIFIED R/F DOOR GEOMETRY & \\
5.0 & POLYMER TECHNOLOGIES FOR ADVANCED INSULATED & 17 \\
& COMPONENTS & \\
& SUMMARY AND CONCLUSIONS & 21 \\
& REFERENCES & 22 \\
& ACKNOWLEDGMENTS
\end{tabular}

\section{LIST OF FIGURES}

PAGE

\begin{tabular}{llc}
\hline 1 & Schematics of Four Categories of R/F Door Construction & 6 \\
2 & k-Value Ranges for Various Thermal Insulations & 9 \\
3 & Infrared Image of Part of a Typical R/F & 10 \\
4 & Frontal View of Model Geometry & 12 \\
5 & Section AA View of Model Geometry & 12 \\
6 & Section BB View of Model Geometry & 13
\end{tabular}

\section{LIST OF TABLES}

\section{PAGE}

1 Model Component Parameter Combinations

2 Model Sheli Component Material Descriptions

3 Model Insulation Component Material Descriptions

4 Calculated Overall, Effective Air-to-Air R-Values of Various R/F

Design Options as Applied to an Assembly Analogous to a

Refrigerator Door 


\section{Executive Summary}

The impending phase-out of chlorofluorocarbons (CFCs) used to expand foam insulation, combined with requirements for increased energy efficiency, make the use of non-CFC-based high performance insulation technologies increasingly attractive. The majority of current efforts are directed at using advanced insulations in the form of thin, flat low-conductivity gas-filled or evacuated orthogonal panels, which we refer to as Advanced Insulation Panels (AIPs). AIPs can be used in composite with blown polymer foams to improve insulation performance in refrigerator/freezers (R/Fs) of conventional design and manufacture. This AIP/foam composite approach is appealing because it appears to be a feasible, near-term method for incorporating advanced insulations into $\mathrm{R} / \mathrm{Fs}$ without substantial redesign or retooling. However, the requirements for adequate flow of foam during the foam-in-place operation impose limitations on the allowable thickness and coverage area of AIPs. This restriction, combined with thermal bridging effects associated with elements such as steel outer shells and surrounding foam, generally allow only relatively small improvements in overall thermal resistance as a result of incorporating AIP/foam composite insulation into conventional foam core $\mathrm{R} / \mathrm{Fs}$.

This report examines design alternatives which may offer a greater increase in overall thermal resistance than is possible with the use of AIP/foam composites in current $\mathrm{R} / \mathrm{F}$ design. These design alternatives generally involve a basic redesign of the $\mathrm{R} / \mathrm{F}$ taking into account the unique requirements of advanced insulations and the importance of minimizing thermal bridging with high thermal resistance insulations. The focus here is on $\mathrm{R} / \mathrm{F}$ doors because they are relatively simple and independent $\mathrm{R} / \mathrm{F}$ components and are therefore good candidates for development of alternative designs. $\mathrm{R} / \mathrm{F}$ doors have significant thermal bridging problems due to the steel outer shell construction. A three dimensional finite difference computer modeling exercise of a $\mathrm{R} / \mathrm{F}$ door geometry was used to compare the overall levels of thermal resistance ( $R$-value) for various design configurations.

One design alternative involves substituting polymer outer shell materials for conventional steel to reduce thermal bridging and edge losses. The computer modeling of a simplified $\mathrm{R} / \mathrm{F}$ door geometry indicated that the percentage of improvement in overall R-values from the use of a polymer outer shell could be $13 \%$ for foam insulation, $15 \%$ for gas-filled AIP/foam insulation, and $18 \%$ for evacuated powder AIP/foam insulation.

Another design alternative includes the use of polymer outer shell materials but discards foam-inplace insulation in favor of a more comprehensive use of advanced insulation technologies. In this case we distinguish between Advanced Insulation Panels (AIPs) and Advanced Insulated Components (AICs). Where an AIP is an insulating panel made for the inside cavity of a component, an AIC is an entire functional component of a product that incorporates an advanced insulation technology. An AIC is thus a thin-walled, hermetic, barrier part with a modified internal atmosphere and an insert consisting of advanced insulation filler material. In the case of $\mathrm{R} / \mathrm{Fs}$, an AIC could be an entire door with accessories attached to it. The barrier envelope, or outer surface, of an AIC would typically be a formed (or molded) polymer part that includes layers of gas and moisture barrier material in a multilayer structure. A gas-filled AIC would have an insert consisting of a multilayer reflective baffle and polymer stiffeners as needed. An 
evacuated powder AIC would, for example, have an insert consisting of compressed and formed powder. AICs would typically not employ blown polymer foam insulations.

The polymer barrier AIC approach offers some significant advantages over using AIP/foam composite in conventional $\mathrm{R} / \mathrm{F}$ design. One of the most important advantages is better resistance to heat transfer resulting from greater thickness and coverage area of the advanced insulation. The polymer outer shell, in addition to causing less thermal bridging than steel, can offer other advantages such as: design freedom, parts reduction, weight reduction, scrap recyclability, and process consolidation. Polymer barrier AICs could be designed for disassembly giving them an advantage in terms of post consumer recyclability over conventional foam core R/Fs because adhesive polyurethane foams make it difficult to disassemble conventional $\mathrm{R} / \mathrm{Fs}$.

Computer modeling of a simplified geometry (representing a two inch $(0.05 \mathrm{~m})$ thick refrigerator door) produced overall $\mathrm{R}$-values for various configurations of insulation and shell materials. The results are summarized below:

$\mathrm{R} / \mathrm{F}$ door configuration

CFC blown foam w/conventional steel outer shell evacuated AIP/foam composite w/conventional steel outer shell gas filled AIP/foam composite w/conventional steel outer shell evacuated AIP/foam composite w/polymer outer shell gas-filled AIP/foam composite w/polymer outer shell evacuated-powder polymer barrier AIC gas-filled polymer barrier AIC
Overall Effective R-value $\mathrm{hr} \cdot \mathrm{ft}^{2} \cdot \circ \mathrm{F} / \mathrm{Btu}\left(\mathrm{m}^{2} \cdot \mathrm{K} / \mathrm{W}\right)$

The individual materials and manufacturing technologies needed to fabricate polymer barrier AICs are generally well developed; however, it appears that there have been no efforts to apply them directly to the production of AICs. Technologies such as coextrusion and lamination could be used to produce thermoplastic multilayer polymer structures with the necessary stiffness and barrier properties. Processes such as twin-sheet thermoforming and coextrusion blow molding could be used to fabricate shaped barrier parts for AICs. Thermal and solvent welding could be used to hermetically join the barrier parts.

The major conclusions of this study are:

(1) Advanced Insulated Components, or AICs, could be mass produced with existing polymer technologies,

(2) AIC R/F components can offer higher levels of thermal resistance than conventional assemblies insulated with foam or AIP/foam composites that have the same thickness,

(3) a considerable amount of development is required and warranted to assess the energy efficiency improvements, economics, manufacturing, and reliability of AICs for R/F applications. 


\subsection{Background and Introduction}

Refrigerator/Freezers (R/Fs) are an important technological concern because of their great utility, widespread use, energy consumption, and contribution to environmental degradation. The energy required to maintain a thermally conditioned interior volume within a $R / F$ depends on how the device is used, the thermal resistance of the $\mathrm{R} / \mathrm{F}$ 's insulated cabinet and doors, and the efficiency of the mechanical systems. The average 1990 model U.S. R/F uses about $50 \%$ less energy than units produced before the early 1970's, with much of this improvement stemming from the use of chlorofluorocarbon (CFC) blown polyurethane foams. U.S. Department of Energy (DOE) standards to go in effect in 1993 will force additional reductions of about $30 \%$ in energy consumption from 1990 levels. DOE standards will be revised again for 1998 and further increases in energy efficiency are likely. Meeting these 1998 standards will likely necessitate higher overall levels of thermal resistance for $\mathrm{R} / \mathrm{F}$. Increasing thermal resistance levels to reduce $\mathrm{R} / \mathrm{F}$ heat gain would, with current polyurethane foam insulation, mean increasing the thickness of the insulating material. This will necessitate either increasing the outside dimensions of appliances or decreasing interior volume. Increasing outside $\mathrm{R} / \mathrm{F}$ dimensions may be problematic for replacement units where existing kitchen spaces are fixed and decreasing interior volume effectively decreases the utility of the product. Thus, particularly for larger model R/Fs, thermal insulations and overall assembly designs that offer high levels of thermal resistance for a given thickness may have considerable value. The phase-out of CFC blowing agents further complicates issues because it will force the use of alternative blowing agents which have a higher thermal conductivity and may result in lower performance foam products available in the future. Hydrochlorofluorocarbon (HCFC) alternative blowing agents can produce foams with thermal performance levels comparable to current CFC-blown foams (with added suppression of radiative heat transfer) but do not fully solve the ozone depletion problem and are considered by many to be a transitional material.

Solid waste disposal problems and rising concern for reuse and recycling of post-consumer materials are likely to eventually be significant issues for the design and manufacture of R/Fs. A redesign of $\mathrm{R} / \mathrm{Fs}$ driven by near-term issues of energy efficiency and CFC elimination can provide an opportunity to design R/Fs with more recycled material content and easier post-consumer recycling of components. The polyurethanes used in foam core $\mathrm{R} / \mathrm{Fs}$ are adhesives which make disassembly difficult and recycling impractical. The U. S. R/F industry currently uses, for example, roughly 300 million pounds ( 140 million $\mathrm{Kg}$ ) of styrenic polymers annually with nearly $100 \%$ recycling of fabrication scrap [Leaversuch 1990]. However this material is not likely to be recycled as postconsumer material because conventional $\mathrm{R} / \mathrm{Fs}$ are not designed for disassembly. This issue is also important for advanced insulation technologies because the relatively high value filler materials (gases, powders, or aerogels) may prove economical to reclaim; thus it may be undesirable to encase the filler materials in adhesive foams.

Four general types of $\mathrm{R} / \mathrm{F}$ design are distinguished. Figure 1 shows these four categories of R/F design as applied to $\mathrm{R} / \mathrm{F}$ doors. The first is conventional polyurethane foam core construction with a steel sheet-metal outer shell and a polymer inner liner; we call this a Conventional R/F. The second design is the same conventional foam core construction but uses Advanced Insulation Panels (AIPs) in composite with foam inside the cavities; we call this a Conventional Advanced 
Insulation Panel/Foam R/F, or Conventional AIP/Foam R/F. The third design involves using a polymer outer-shell, instead of steel sheet-metal, with a polymer inner liner and either foam or AIP/foam composite insulation; we refer to this design as a Polymer Shell R/F. The fourth design involves a different construction where the $\mathrm{R} / \mathrm{F}$ cabinet and doors primarily consist of Advanced Insulated Components (AICs), which are functional, hermetic-gas-barrier polymer components that encapsulate advanced insulations; we call this an Advanced R/F.

This report intends to provide a preliminary discussion of issues related to the design of, and motivation for, Advanced Insulated Components in R/F applications. Doors are the primary R/F components used to exemplify the $\mathrm{R} / \mathrm{F}$ designs. Specific designs are beyond the scope of this report. We discuss:

(1) the general nature of advanced insulation technologies making a distinction between Advanced Insulation Panels (AIPs) and Advanced Insulated Components (AICs),

(2) The importance of thermal bridging and spatial heat flows noting such thermal resistance problems for Conventional R/Fs and Conventional AIP/Foam R/Fs,

(3) a three-dimensional computer modeling exercise which calculates the overall thermal resistance for a consistent flat geometry analogous to a $\mathrm{R} / \mathrm{F}$ door with various combinations of shell materials and insulations, and

(4) a summary of polymer technologies and issues related to Advanced Insulated Components and Advanced R/Fs. 


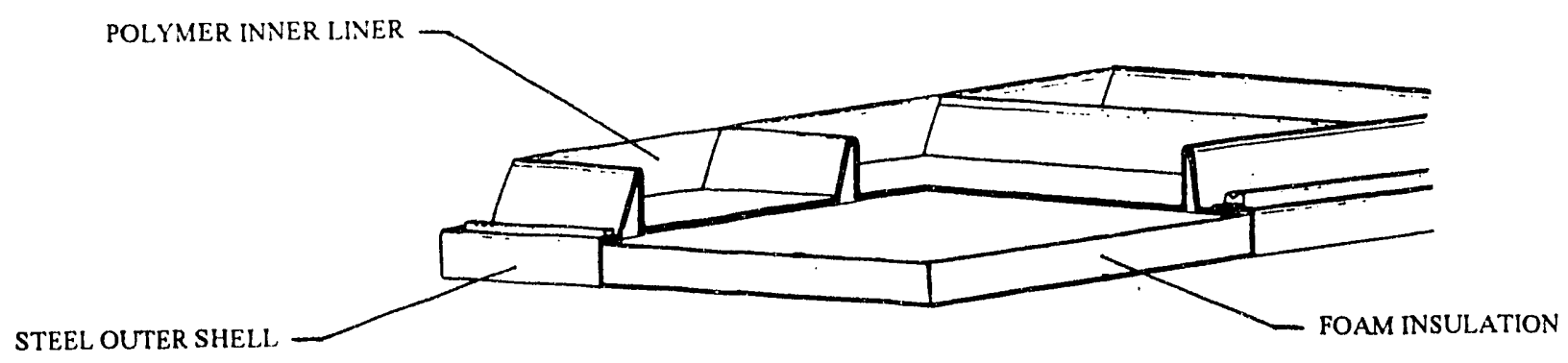

Conventional R/F
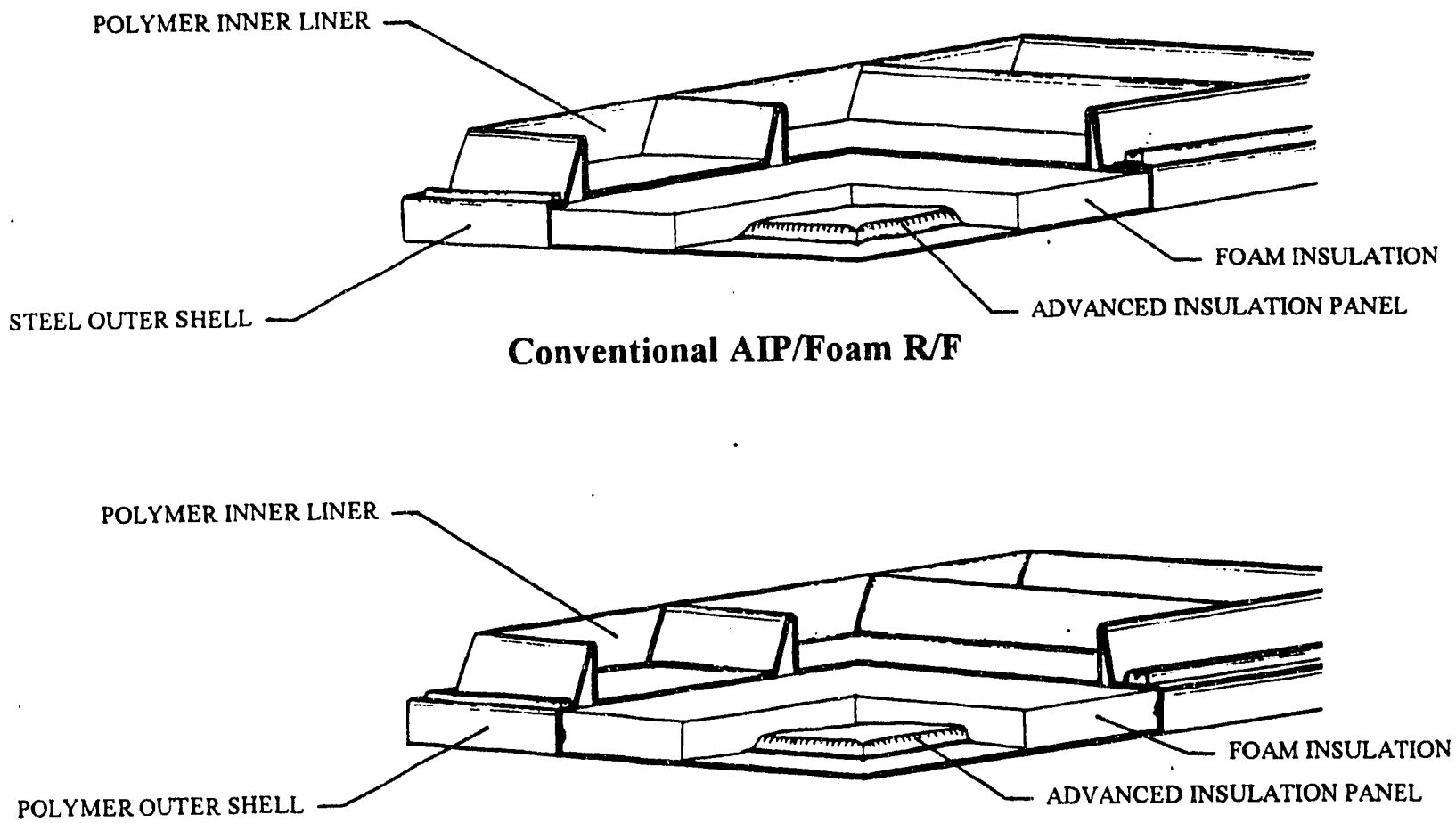

\section{Polymer Shell R/F with AIP/Foam Composite}

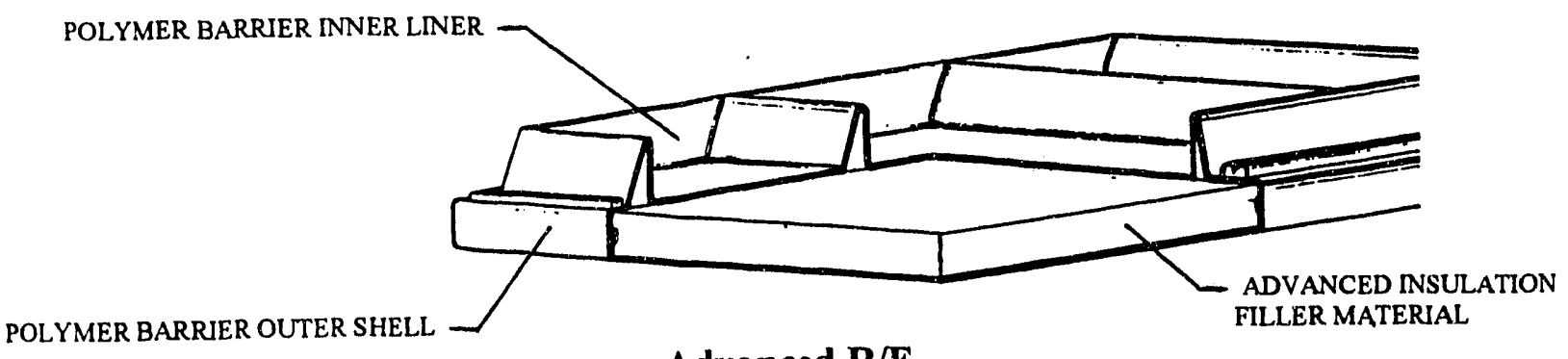

Advanced R/F

FIGURE 1. Schematics of Four Categories of R/F Door Construction 


\subsection{Advanced Insulation Technologies}

Advanced insulation technologies can yield devices with high levels of thermal resistance for a given thickness and offer the potential to reduce $\mathrm{R} / \mathrm{F}$ heat gain without increasi.ng insulation thickness or using CFCs. Advanced insulation technologies generally employ a hermetic barrier envelope to maintain a modified atmosphere within a filler material, yielding higher levels of thermal performance than can be obtained with atmospheric air in (or diffusing appreciably into) a volume of insulation. Advanced insulations include both vacuum-based systems and atmosphericpressure, low-conductivity gas-based systems. Gas-based insulations include Gas-Filled Panels (GFPs), which use a multi-cavity reflective filler material [Griffith 1991], and gas-filled conventional insulation materials. Vacuum-based insulations include: powder evacuated panels (PEP or VIP) [Kollie 1991], aerogel evacuated panels [Hunt 1991], and evacuated panels using glass fibers or foams as filler materials. Vacuum-based insulations that use filler materials with very small void size, such as aerogels and dense powders, can operate effectively at internal pressures of up to around 0.01 to 0.1 atmosphere and are referred to as soft-vacuum insulations. The filler material used for soft-vacuum insulation supports the barrier envelope against the pressure of the atmosphere. While vacuum-based insulation systems have been used widely in the past, (e.g. the Thermos ${ }^{\mathrm{TM}}$ bottle and cryogenic equipment) these are typically hard-vacuum (internal pressures on the order of $1 \times 10^{-7}$ atmosphere) systems with cylindrical geometries. Soft-vacuum and gas-filled modern advanced insulations do not require completely gas impermeable barrier envelopes enabling the use of polymer barrier materials with relatively low thermal conductivity rather than impermeable metal barriers that have high thermal conductivity. Modern advanced insulations can be effective in geometries other than cylindrical because of the use of relatively low thermal conductivity barriers and filler materials that support pressure differences (if applicable). It is useful to distinguish between two general embodiments of modern advanced insulation technologies, Advanced Insulation Panels (AIPs) and Advanced Insulated Components (AICs); these are discussed below.

Advanced Insulation Panels, or AIPs, are currently the typical configuration for advanced insulations and can be described as thin, flat, orthogonal panels of variable size; their outer surfaces are comprised of a thin barrier film which is sealed around the perimeter. Thermal conductivities, or k-values, of AIPs are typically quantified by "center-of-panel" k-values which can be lower than the overall, or average, $k$-value of a panel because of solid conduction through the barrier envelope material around the edge (barrier thermal bridging effects). The most widely considered approach for incorporating AIPs into R/Fs involves using them in composite with foam-in-place, closed cell, polyurethane foam (PUR); we refer to this approach as AIP/foam composite. AIPs would be located within the insulated cavities of the R/F cabinet and doors, adhered to either the inside of steel outer-shell or to the outside of the inner polymer liner. PUR would be foamed around the AIPs in the same fashion currently used for the manufacture of Conventional R/Fs. AIP/foam composite insulation requires a thickness of PUR which is sufficient for adequate flow of foam during fabrication; this limits the thickness available for AIPs. The PUR of the AIP/foam composite would continue serving to stiffen the R/F; this limits the area available to cover with AIPs. 
Advanced Insulated Components (AICs) differ from AIPs in that the barrier envelope is not necessarily a thin film in a flat geometry. An AIC barrier envelope can be shaped into a useful part and would typically be comprised of a stiff barrier material. We define an AIC as a thinwalled, hermetic, gas-barrier part where the interior volume of the part is an advanced insulation technology and the part itself is a functional device or necessary component of a product. A dewar flask is an example of an AIC using a hard-vacuum insulation technology and a metal barrier envelope. Residential windows, of the type known as low-e gas-filled, are examples of AICs using gas-filled insulation technology and a predominately glass barrier envelope. However, this report is primarily concerned with AICs that would use modern soft-vacuum* or gas-filled advanced insulations and polymer barrier envelopes; it appears that no efforts have been made to prototype or produce such AICs. Polymers are logical partners to AICs because they have relatively low thermal conductivities and can act as gas and moisture barriers. A gas-filled AIC would, for example, have an insert consisting of a multilayer reflective baffle and polymer stiffeners as needed. An evacuated AIC would, for example, have an insert consisting of compressed and formed powder. AICs would typically not employ blown polymer foam insulations. We define Advanced R/Fs as a class of R/Fs that would use AICs as the basic elements of cabinets and doors. For example, an AIC R/F door could be a single AIC with accessories attached to it. In the context of Advanced R/Fs we discuss only modern gas-filled or soft-vacuum advanced insulation technologies and are primarily interested in polymer barrier envelopes. AICs may offer advantages over AIP/foam composites for using advanced insulation technologies in R/F applications because in an AIC: (1) barrier thermal bridging effects are combined with otherwise necessary elements of the product construction, (2) barrier envelope materials can be thicker (providing an improved barrier to gases and moisture) and (3) a foam insulation composite is not used, allowing increased thickness and larger coverage area of advanced insulation.

Figure 2 summarizes the thermal conductivities, or k-values, of various thermal insulation materials and technologies. These values are a mix of literature numbers, recent (unpublished) test measurements and estimates and are presented solely to introduce the reader to the relative performance levels of various insulations. For advanced insulations these k-values would correspond to "center-of-panel" k-values. Recyclable foams are thermoplastic, closed-cell rigid foams, such as expanded polystyrene.

\footnotetext{
* We do not discuss hard vacuum technologies because their performance is roughly similar to soft vacuum technologies yet pose greater barrier and thermal bridging design problems.
} 


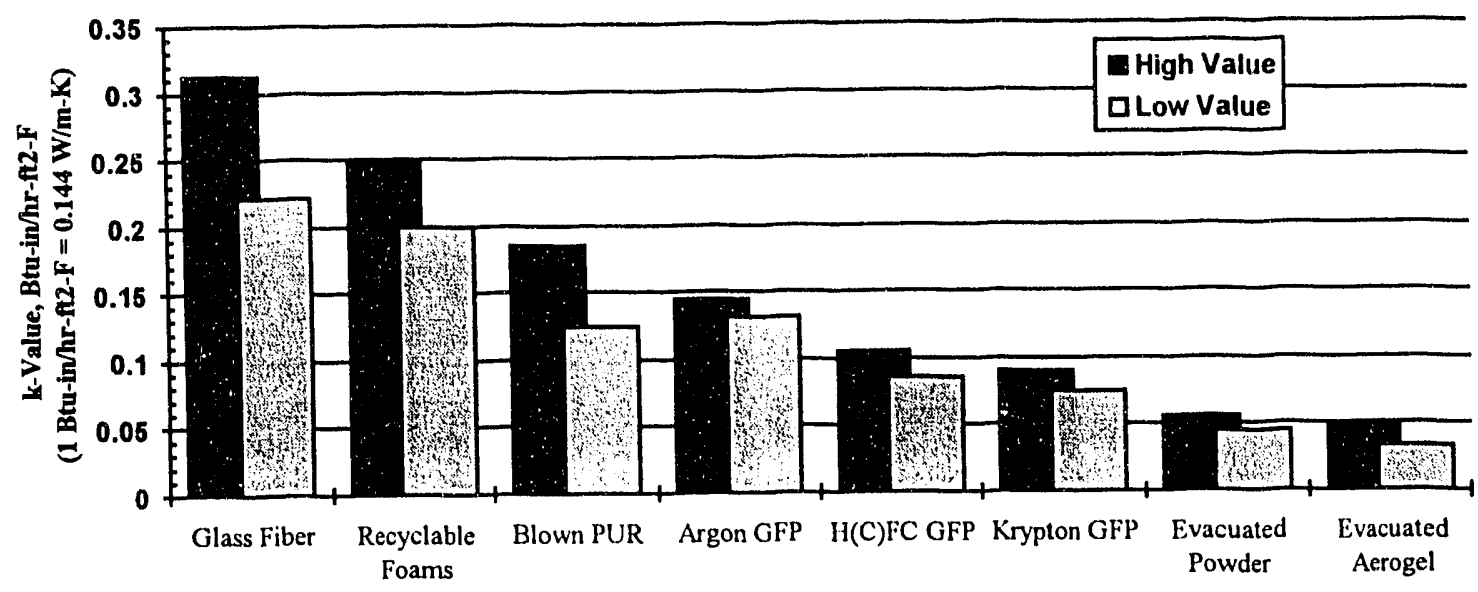

FIGURE 2. k-Value Ranges for Various Thermal Insulations

\subsection{Thermal Resistance Issues for Conventional R/F Design}

While the thermal resistance of an insulated system depends strongly on the thermal conductivity, or $\mathrm{k}$-value, of the insulation employed, the overall level of thermal resistance can be strongly effected by the characteristics of the entire assembly. An attempt to improve the overall level of thermal resistance in a $\mathrm{R} / \mathrm{F}$ should address the whole system in addition to insulation $\mathrm{k}$-values. The $k$-value is only an accurate quantifier for heat flow in situations where heat transfer is uniform and directed perpendicular to the insulation; such one-dimensional heat flow is rare in real insulated systems. Thermal bridges and two- and three-dimensional heat flows typically cause the effective level of thermal resistance in a real system to be significantly less than simple k-values would indicate. Thermal bridges are relatively high conductivity elements of an insulated system which extend in the direction of heat flow and have a significant detrimental effect on the overall thermal resistance of the system. Two- and three-dimensional, or spatial, heat flows are caused by the presence of slightly higher conductivity materials in a system, such as foam in an AIP/foan: composite, and can also decrease the overall thermal resistance of the system. Furthermore, thermal bridging and three-dimensional heat transfer effects become increasingly significant for higher levels of thermal resistance; this is partly because the heat flow through thermal bridges becomes a larger portion of the total heat flow at higher levels of thermal resistance and partly because more heat will flow through the thermal bridges. This increased importance of thermal bridging is reflected in the results of the modeling exercise presented in the next section. The significance of these heat transfer effects may motivate a complete redesign of the domestic R/F.

We note five examples of problematic spatial heat flows and thermal bridging in Conventional $\mathrm{R} / \mathrm{Fs}$ and Conventional AIP/Foam R/Fs.

(1) Steel outer shell materials of cabinets and doors generally wrap around to the cold side at their edges. Even in very thin sections, high conductivity steel creates significant thermal bridges, which reduces overall performance and frequently results in the need for anti-sweat heaters. 
(2) Mechanical system throughputs and other miscellaneous elements that extend across the insulated envelope, such as hinge and shelf brackets, can create thermal bridging and/or infiltration and problems for locating AIPs

(3) Door gaskets are generally not good insulators and can allow infiltration as the gaskets degrade over time.

(4) Advanced Insulation Panels cannot cover the full area of the R/F shell so there is foam surrounding the panels. The regions of lower thermal resistance foam in the composite matrix provide pathways for heat to bypass the AIPs, which substantially reduces their effectiveness.

(5) Solid conduction through an AIP's barrier envelope material can enable heat to flow around the advanced insulation. This problem has received considerable attention in the development of AiPs because it restricts the barrier materials that are acceptable for AIPs.

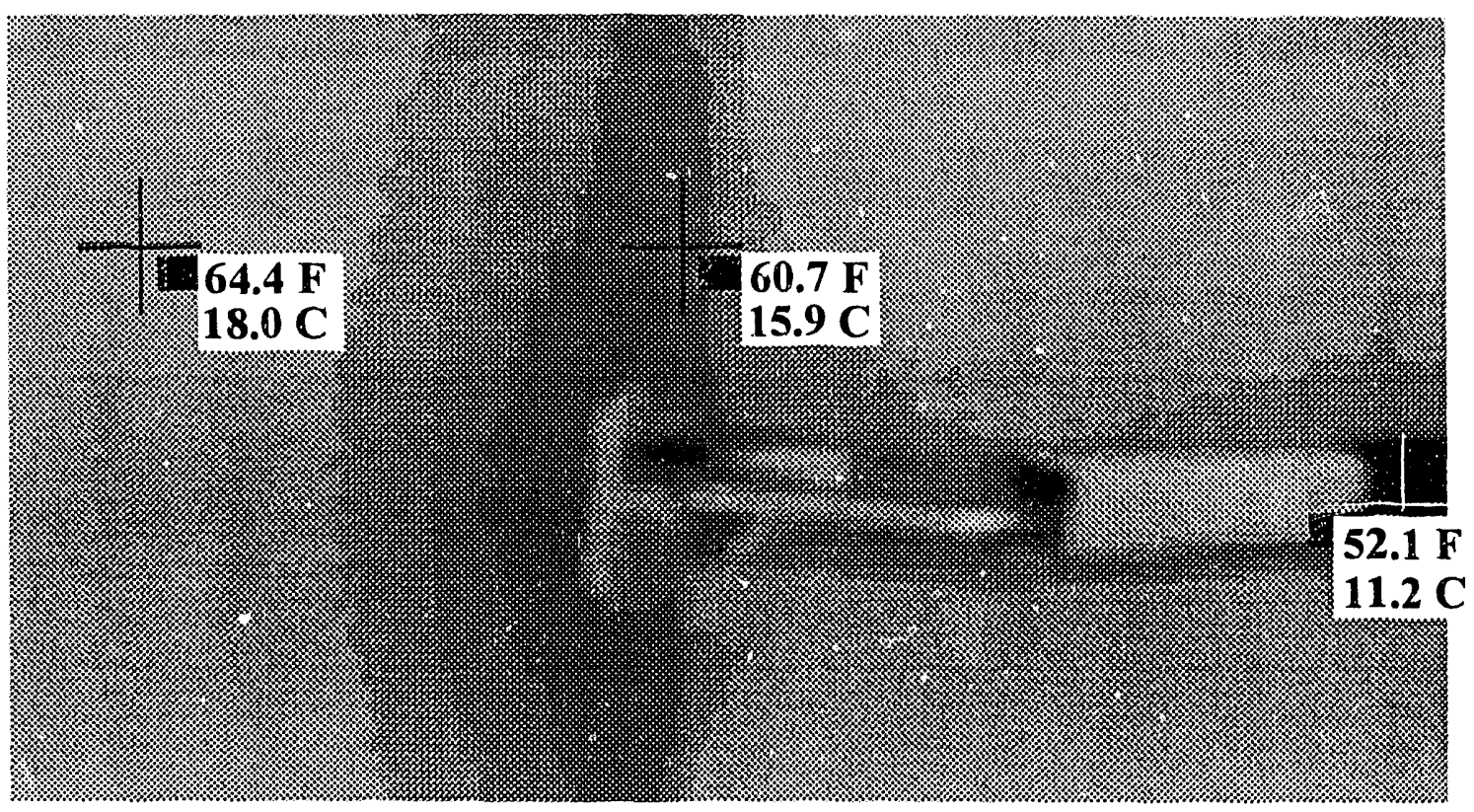

FIGURE 3 Infrared Image of Part of a Typical R/F

Figure 3 is an infrared image (thermogram) showing the effects of thermal bridges on the exterior surface temperatures of a typical $\mathrm{R} / \mathrm{F}$. The view is a close up of the left side and two iront doors near the hinge. The unit is a fairly efficient 1987 model, top mount, $18 \mathrm{ft}^{3} \mathrm{U}$.S. R/F in normal use with anti-sweat heaters switched off. Darker shades of gray in Figure 31 epresent lower surface temperatures and hence greater heat flow. Figure 3 shows surface temperatures for three spots in the image; accuracy is estimated at $3.5^{\circ} \mathrm{F}\left(2^{\circ} \mathrm{C}\right)$ absolute and $0.4^{\circ} \mathrm{F}\left(0.2^{\circ} \mathrm{C}\right)$ relative. The $\mathrm{R} / \mathrm{F}$ unit is operating in an environment at roughly $68^{\circ} \mathrm{F}\left(20^{\circ} \mathrm{C}\right)$ with typical inside conditions. 


\subsection{Three-Dimensional Heat Transfer Modeling of a Simplified R/F Door Geonetry}

A three-dimensional computer modeling exercise was conducted for a preliminary, quantitative comparison of the overall levels oi thermal resistance for various configurations of $\mathrm{R} / \mathrm{F}$ doors based on four categories of $\mathrm{R} / \mathrm{F}$ design: Conventional R/Fs, Conventional AIP/Foam R/Fs, Polymer Shell R/Fs, and Advanced R/Fs. The modeling is also useful for an indication of the significance of thermal bridges and spatial heat flows (particularly examples 1 , and 4 in the previous section) in such assemblies. A specific model of a R/F door was not modeled, rather the mcdel was of a flat assembly with geometry analogous to a refrigerator door. The exercise calculated the overall, or average, thermal resistance (effective R-Value) of the assembly for parametric modeling runs using different combinations of insulations and outer-shell materials. The model geometry and parameters were developed by the authors at Lawrence Berkeley Laboratory (LBL), and the computer simulations were performed at Oak Ridge National Laboratory (ORNL) using HEATING-7, a public domain finite difference heat transfer solution code.

The model geometry is shown in figure 4, figure 5, and figure 6 with dimensions in inches ( 1 inch $=0.0254 \mathrm{~m})$. The vertical assembly was modeled with horizontal heat flow and air temperatures of $\mathrm{O}^{\circ} \mathrm{F}\left(-17.8^{\circ} \mathrm{C}\right)$ on the cold side and $75^{\circ} \mathrm{F}\left(23.9^{\circ} \mathrm{C}\right)$ on the warm side. Air film heat transfer coefficients were taken as $1.46 \mathrm{Btu} / \mathrm{hr} \cdot \mathrm{ft}^{2 \circ} \mathrm{F}\left(8.3 \mathrm{~W} / \mathrm{m}^{2} \cdot \mathrm{K}\right)$ for all surfaces. There are five separate components (A,B,C, D, and E) of the model which are shown in figure 5 and figure 6 . Table 1 lists the materials used for these components for each test run in code form with descriptions and thermal conductivity values referenced in Table 2 (shell materials: A and B) and Table 3 (insulation materials: C, D, and E). The k-values used for the modeling are a mix of literature numbers, recent (unpublished) test measurements and estimates. For advanced insulations these k-values would correspond to "center-of-panel" performances. The k-values for multilayer, gasbarrier thermoplastic sheet in Table 2 are assumed. AIP coverage area is $75 \%$ for test runs 3,4 , $5,6,8$, and 9 which use AIP/foarn composite insulation. 


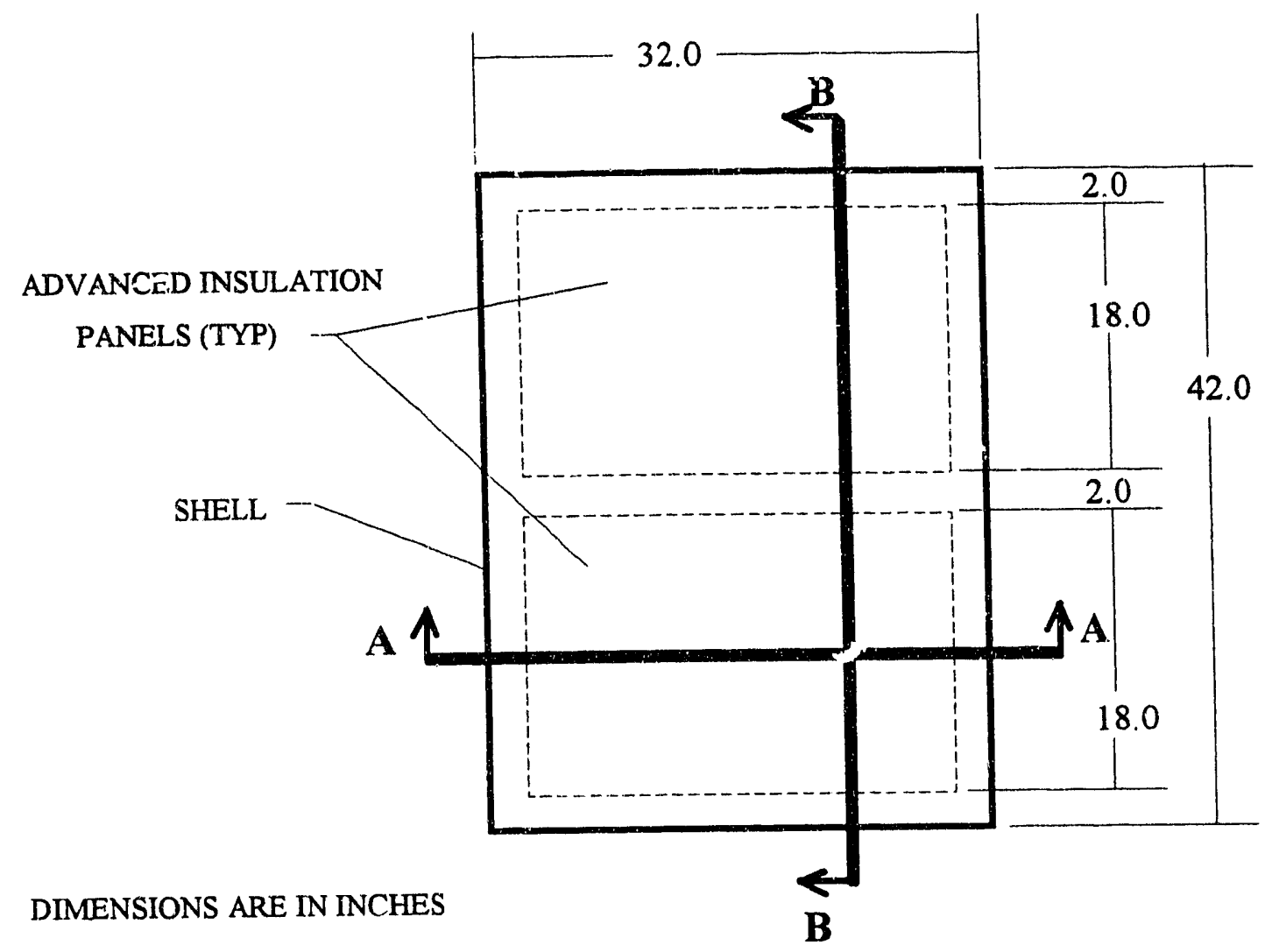

FIGURE 4. Frontal View of Model Geometry

WARM-SIDE AMBIENT CONDITIONS

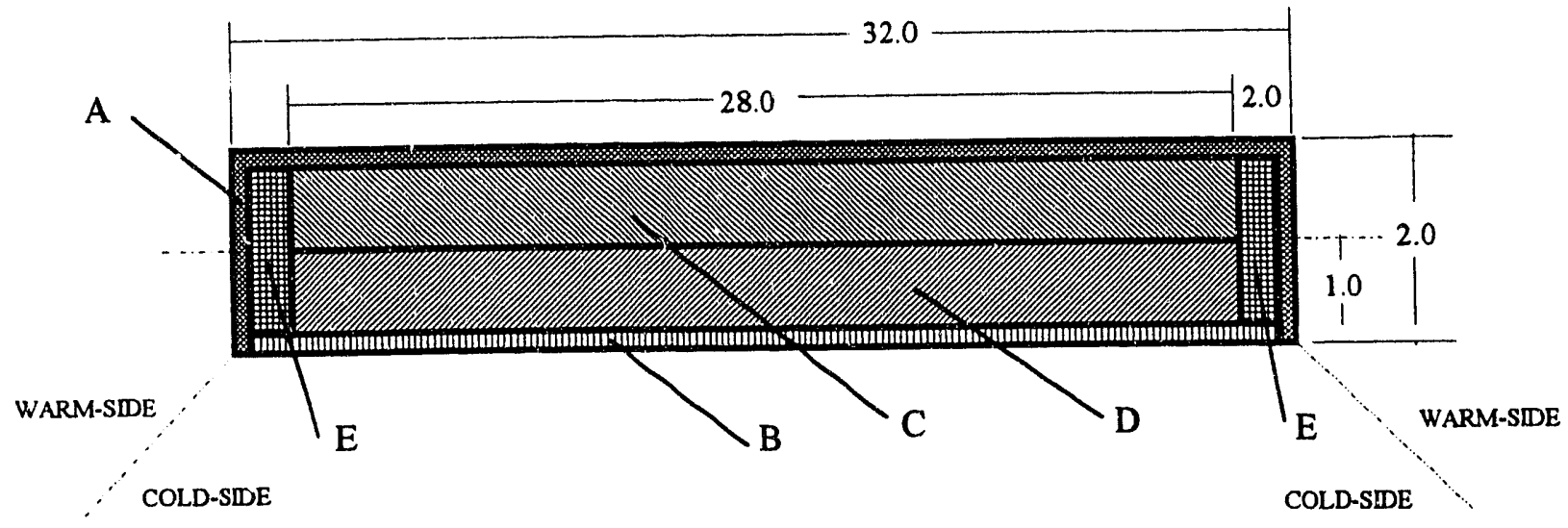

COLD-SIDE CONDITIONS

DIMENSIONS $\Lambda$ RE $\mathbb{N}$ INCHES

FIGURE 5. Section AA View of Model Geometry 


\section{WARM-SIDE AMBIENT CONDITIONS}

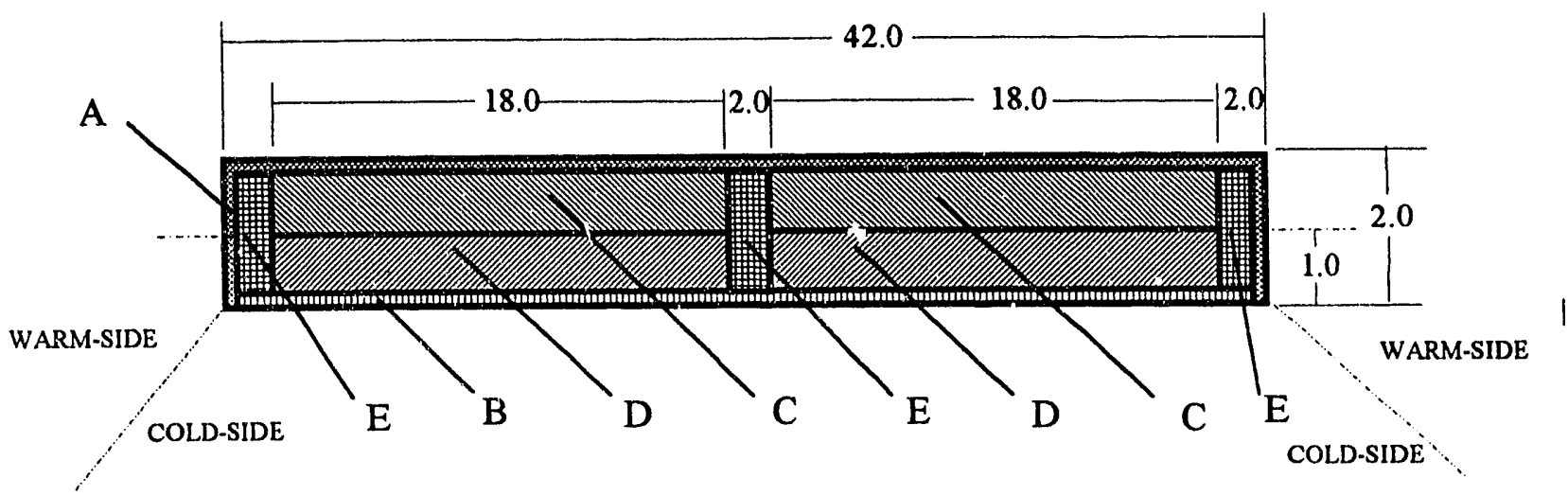

COLD-SIDE CONDITIONS

DIMENSIONS ARE IN INCHES

Figure 6: Section BB View of Model Geometry

TABLE 1. Model Component Parameter Combinations

\begin{tabular}{|c|c|c|c|c|c|c|}
\hline $\begin{array}{l}\text { Modeling } \\
\text { Test Run }\end{array}$ & Related R/F Design & A & B & $\mathrm{C}$ & D & $\mathrm{E}$ \\
\hline 1 & Conventional R/F, CFC-PUR & ST & $\mathrm{ABS}$ & PUR & PUR & PUR \\
\hline 2 & $\begin{array}{c}\text { Conventional R/F, non-CFC- } \\
\text { PUR }\end{array}$ & ST & ABS & APUR & APUR & APUR \\
\hline 3 & Conventional AIP/Foam R/F, & ST & $\mathrm{ABS}$ & PEP & APUR & APUR \\
\hline 4 & $\begin{array}{c}\text { Evacuated Powder w/non- } \\
\text { CFC-PUR } \\
\end{array}$ & ST & ABS & APUR & PEP & APUR \\
\hline 5 & Conventional AIP/Foam R/F, & $\mathrm{ST}$ & $\mathrm{ABS}$ & GFP & APUR & APUR \\
\hline 6 & Gas-Fill w/non-CFC-PUR & ST & $\mathrm{ABS}$ & APUR & GFP & APUR \\
\hline 7 & $\begin{array}{c}\text { Polymer Shell R/F, non- } \\
\text { CFC-PUR }\end{array}$ & $\mathrm{TP}$ & $\mathrm{ABS}$ & APUR & APUR & APUR \\
\hline 8 & $\begin{array}{c}\text { Polymer Shell R/F, Fowder } \\
\text { Evacuated Panel w/non- } \\
\text { CFC-PUR } \\
\end{array}$ & $\mathrm{TP}$ & ABS & PEP & APUR & APUR \\
\hline 9 & $\begin{array}{c}\text { Polymer Shell R/F, Gas- } \\
\text { Filled Panel w/non-CFC- } \\
\text { PUR } \\
\end{array}$ & TP & $\mathrm{ABS}$ & GFP & APUR & APUR \\
\hline 10 & "AIC", non-CFC-PUR & M1 & M2 & APUR & APUR & APUR \\
\hline 11 & AIC, Evacuated Powder & M1 & M2 & PEP & PEP & PEP \\
\hline 12 & AIC, Gas-Filled & M1 & M2 & GFP & GFP & GFP \\
\hline 13 & $\begin{array}{l}\text { AIC, Gas-Fill w/non-CFC- } \\
\text { PUR }\end{array}$ & M1 & M2 & GFP & GFP & APUR \\
\hline
\end{tabular}


TABLE 2 Model Shell Component Material Descriptions

\begin{tabular}{|c|l|c|c|}
\hline Code & Material & $\begin{array}{c}\text { Thickness } \\
\text { inch } \\
(\mathrm{m})\end{array}$ & $\begin{array}{c}\mathrm{k}-\text { Values } \\
\mathrm{Btu} \cdot \mathrm{in} / \mathrm{hr} \cdot \mathrm{ft}^{2} \cdot{ }^{\circ} \mathrm{F} \\
(\mathrm{W} / \mathrm{m} \cdot \mathrm{K})\end{array}$ \\
\hline ST & Steel & $0.024(0.00061)$ & $400.0(57.6)$ \\
\hline ABS & $\begin{array}{l}\text { Acrylonitrile Butadiene } \\
\text { Styrene }\end{array}$ & $0.060(0.0015)$ & $1.9(0.27)$ \\
\hline TP & $\begin{array}{l}\text { Engineering } \\
\text { Thermoplastic }\end{array}$ & $0.15(0.0038)$ & $2.0(0.29)$ \\
\hline M1 & $\begin{array}{l}\text { Multilayer Gas Barrier } \\
\text { Polymer }\end{array}$ & $0.15(0.0038)$ & $2.0(0.29)$ \\
\hline M2 & $\begin{array}{l}\text { Multilayer Gas Barrier } \\
\text { Polymer }\end{array}$ & $0.060(0.0015)$ & $2.0(0.29)$ \\
\hline
\end{tabular}

TABLE 3 Model Insulation Component Material Descriptions

\begin{tabular}{|l|l|c|}
\hline Code & Insulation Material & $\begin{array}{c}\mathrm{k}-\mathrm{Values} \\
\mathrm{Btu} \cdot \mathrm{in} / \mathrm{hr} \cdot \mathrm{ft}^{2} \cdot{ }^{\circ} \mathrm{F}(\mathrm{W} / \mathrm{m} \cdot \mathrm{K})\end{array}$ \\
\hline PUR & $\begin{array}{l}\text { CFC-Blown Polyurethane } \\
\text { Closed Cell Foam }\end{array}$ & $0.14(0.020)$ \\
\hline APUR & $\begin{array}{l}\text { Non-CFC Blown } \\
\text { Polyurethane Foam }\end{array}$ & $0.15(0.022)$ \\
\hline GFP & $\begin{array}{l}\text { Gas-Filled Advanced } \\
\text { Insulation }\end{array}$ & $0.088(0.0127)$ \\
\hline PEP & $\begin{array}{l}\text { Evacuated Powder } \\
\text { Advanced Insulation }\end{array}$ & $0.045(0.0065)$ \\
\hline
\end{tabular}

The calculated results for each model test run are listed in Table 4 as effective R-values [Childs 1992]. These effective $R$-values quantify the overall resistance to heat flow (units of $\mathrm{hr} \cdot \mathrm{ft}^{2} \cdot{ }^{\circ} \mathrm{F} / \mathrm{Btu}$ or $\mathrm{m}^{2} \cdot \mathrm{K} / \mathrm{W}$ ), including two air film resistances, based on the total calculated heat flow and the area of the main surface oriented perpendicular to the general direction of heat flow. Thermal bridging effects of the assembly edges (external perimeter surface areas oriented parallel to the direction of heat flow) are included in the calculated heat flow but the effective R-values do not apply to these edge areas. AIPs were modeled as homogeneous materials with no barrier thermal bridging effects with the intent of simplifying the model and focusing on thermal bridging effects of the outer-shell materials and the foam in AIP/foam composites. Table 4 also provides an Rvalue for just the insulations which is based on a simple, area weighted, one-dimensional summation of $k$-values. These one-dimensional values $c$ not include the shell materials or any effects of spatial heat flows or thermal bridging and are only presented to show the relative significance of these three-dimensional effects for the different design cases. 
TABLE 4 Calculated Overall, Effective Air-to-Air R-Values of Various R/F Design Options as Applied to an Assembly Analogous to a Refrigerator Door.

\begin{tabular}{|c|c|c|c|}
\hline $\begin{array}{l}\text { Modeling } \\
\text { test run }\end{array}$ & R/F Door Design Description & $\begin{array}{c}\text { Three-Dimensional } \\
\text { Computer Simulation } \\
\text { Results } \\
\mathrm{hr} \cdot \mathrm{ft}^{2} \cdot{ }^{\circ} \mathrm{F} / \mathrm{Btu}\left(\mathrm{m}^{2} \cdot \mathrm{K} / \mathrm{W}\right)\end{array}$ & $\begin{array}{l}\text { One-Dimensional } \\
\text { Area Weighted Sum of } \\
\text { Insulation R-Values } \\
\mathrm{hr} \cdot \mathrm{ft}^{2} \cdot{ }^{\circ} \mathrm{F} / \mathrm{Btu}\left(\mathrm{m}^{2} \cdot \mathrm{K} / \mathrm{W}\right)\end{array}$ \\
\hline 1 & Conventional R/F, CFC-PUR & $9.03(1.59)$ & $13.69(2.41)$ \\
\hline 2 & Conventional R/F, non-CFC-PUR & $8.69(1.53)$ & $12.77(2.25)$ \\
\hline 3 & \multirow{2}{*}{$\begin{array}{c}\text { Conventional AIP/Foam R/F, } \\
\text { Evacuated Powder w/non-CFC-PUR }\end{array}$} & $11.11(1.96)$ & $21.34(3.76)$ \\
\hline 4 & & $11.17(1.97)$ & $21.59(3.80)$ \\
\hline 5 & \multirow{2}{*}{$\begin{array}{l}\text { Conventional AIP/Foam R/F, } \\
\text { Gas-Filled Panel w/non-CFC-PUR }\end{array}$} & $9.70(1.71)$ & $15.83(2.79)$ \\
\hline 6 & & $9.72(1.71)$ & $15.94(2.81)$ \\
\hline 7 & Polymer Shell R/F, non-CFC-PUR & $9.82(1.73)$ & $11.93(2.10)$ \\
\hline 8 & $\begin{array}{l}\text { Polymer Shell R/F, Powder Evacuated } \\
\text { Panel w/non-CFC-PUR }\end{array}$ & $13.09(2.31)$ & $19.92(3.51)$ \\
\hline 9 & $\begin{array}{l}\text { Polymer Shell R/F, Gas-Filled Panel } \\
\text { w/non-CFC-PUR }\end{array}$ & $11.15(1.96)$ & $14.75(2.60)$ \\
\hline 10 & "AIC", non-CFC-PUR & $9.80(1.73)$ & $11.93(2.10)$ \\
\hline 11 & AIC, Evacuated Powder & $18.80(3.31)$ & $39.78(7.01)$ \\
\hline 12 & AIC, Gas-Filled & $13.50(2.38)$ & $20.34(3.58)$ \\
\hline 13 & $\begin{array}{l}\text { AIC, Gas-Fill w/non-CFC-PUR for } \\
\text { stiffness }\end{array}$ & $12.17(2.14)$ & $17.43(3.07)$ \\
\hline
\end{tabular}

While the calculated R-values in Table 4 do not necessarily correspond directly to any real or expected R/F component performances, they are useful for comparing the effective thermal performances of various methods of insulating and constructing R/F doors. Meaningful and interesting comparisons include: (1) three-dimensional results versus simple one-dimensional expectations (2) the change in overall thermal resistance levels due to reduced thermal bridging effects from substituting a polymer outer shell for the conventional steel, and (3) thermal performance levels of AICs versus AIP/foam composite insulated assemblies.

Comparing the overall effective $\mathrm{R}$-value results of the three-dimensional model to the simple total $\mathrm{R}$-values calculated based on an area weighted one-dimensional summation (using "center of panel" k-Values), provides an indication of the significance of three dimensional heat flows and thermal bridging effects. The effective average performance of the steel outer-shell assembly insulated with polyurethane foam (Conventional $\mathrm{R} / \mathrm{F}$ ) is about $67 \%$ of what a simple onedimensional R-value assessment would indicate. Similarly the effective average resistance with gas-filled AIP/foam composite insulation is about $61 \%$ and an evacuated powder AIP/foam composite insulation is about $52 \%$ of what simple one-dimensional assessments indicate. Note that these calculated results do not take into account any barrier material edge effects for the AIPs; these edge effects depend on the type and thickness of the barrier envelope material and would further reduce the effective R-values of the AIP/foam composites if included. These results show a progression of greater differences between effective $\mathrm{R}$-values and simple onedimensional $\mathrm{R}$-values for higher performance insulation (e.g. foam at $67 \%$, gas-filled AIP/foam at 
$61 \%$, and evacuated powder AIP/foam at $52 \%$ ) within the same shell assemblies. This progression supports the assertion that thermal bridging and spatial heat transfer effects are more significant for higher levels of thermal resistance.

The model results provide an indication of the improvements in overall thermal resistance which may be obtained by substituting a polymer for steel in the outer-shells of $\mathrm{R} / \mathrm{F}$ doors. Thermal conductivities of the pnlymer are lower than steel by a factor of about 200 but the thickness of the polymer shell is greater t'ian the steel by a factor of about six. Comparing test run 7 to test run 2 reveals an increase in cifective $\mathrm{R}$-value of about $13 \%$ for a Polymer Shell $\mathrm{R} / \mathrm{F}$ door assembly using non-CFC foam insulation. This level of resistance is about $9 \%$ higher than that calculated for a Conventional R/F door using CFC-blown foam insulation (test run 1); this indicates that such a reduction in thermal bridging can compensate for performance decreases associated with substituting non-CFC foams for CFC foams (model assumes a 7\% decrease in $\mathrm{R}$-value for alternative blowing agent foam). Comparing test run 8 to test runs 3 and 4 indicates an increase in effective R-value of about $17.5 \%$ for a Polymer Shell R/F door assembly using evacuated powder AIP/foam composite insulation. Comparing test run 9 to test runs 5 and 6 indicates an increase in effective R-value of alout $15 \%$ for a Polymer Shell R/F door assembly using gas-filled AIP/foam composite insulation. These results show a greater percentage of improvement for higher performance thermal insulations indicating once again that thermal bridging is of increased importance for higher levels of thermal resistance.

The computer model calculated effective R-values for Advanced Insulated Components (AICs) with $\mathrm{R} / \mathrm{F}$ door geometries (test runs 11,12, and 13). The outer-shell and the inner-liner inaterials of an AIC are multilayer thermoplastic barrier structures and the entire internal volume of the assembly contains homogenous advanced insulation material. Test run 11 is an evacuated powder AIC and test run 12 is a gas-filled AIC. Test run 13 is also a gas-filled AIC but with foam around the perimeter and across the center for added stiffness (Model Component $E$ in Figure 4). The calculated effective $\mathrm{R}$-value of the powder vacuum AIC is about $47 \%$, and a gas-filled AIC is about $66 \%$, of what a simple one-dimensional R-value assessment would indicate. The overall performance levels for the AICs are significantly higher than the corresponding AIP/foam composite insulated polymer shell assemblies because of the greater thickness and complete coverage of advanced insulation. The evacuated powder AIC had a calculated effective R-value that was $69 \%$ better than a Conventional R/F door assembly using evacuated-powder AIP/foam composite insulation and $44 \%$ better than a Polymer Shell R/F door assembly using evacuatedpowder AIP/foam composite insulation. The gas-filled AIC had a calculated effective R-value that was $39 \%$ better than a Conventional R/F door assembly using gas-filled AIP/foam composite and $21 \%$ better than a Polymer Shell R/F door assembly using gas-filled AIP/foam composite insulation.

The model results alsu enable comparing gas-filled and evacuated powder advanced insulations. Test runs $5,6,9,12$, and 13 calculated the effective thermal resistance levels for a refrigerator door geometry using gas-filled advanced insulation technology with a k-value of $0.088 \mathrm{Btu} \cdot \mathrm{in} / \mathrm{hr}$. $\mathrm{ft}^{2}{ }^{\circ} \mathrm{F}(0.0127 \mathrm{~W} / \mathrm{m} \cdot \mathrm{K})$ and test runs $3,4,8$, and 11 used evacuated powder advanced insulation technology with a $\mathrm{k}$-value of $0.045 \mathrm{Btu} \cdot \mathrm{in} / \mathrm{hr} \cdot \mathrm{ft}^{2} \cdot{ }^{\circ} \mathrm{F}(0.0065 \mathrm{~W} / \mathrm{m} \cdot \mathrm{K})$. Comparing evacuatedpowder advanced insulation to gas-filled advanced insulation for the same $\mathrm{R} / \mathrm{F}$ door designs yields 
evacuated powder system resistance levels which are $15 \%$ higher with Conventional AIP/Foam $\mathrm{R} / \mathrm{F}$ design, $17 \%$ higher with Polymer Shell R/F design, and 39\% higher with an Advanced R/F design. Gas-filled AIPs used with a Polymer Shell R/F design showed a thermal resistance that equals that of evacuated powder AIP/foam composite in a Conventional R/F design. Gas-filled AICs showed a thermal resistance level that was $21 \%$ higher than evacuated powder AIP/foam composite in a Conventional $\mathrm{R} / \mathrm{F}$ design and $3 \%$ higher than evacuated powder AIP/foam composite in a Polymer Shell R/F design.

The following conclusions can be drawn from the results of this modeling exercise:

(1) A simple one-dimensional analysis of insulation R-values significantiy overestimates the effective level of thermal resistance for an assembly analogous to a R/F door.

(2) Substituting polymer material for steel in the outer shell of a R/F door may provide a significant increase in the effective level of thermal resistance.

(3) $\mathrm{R} / \mathrm{F}$ doors constructed as Advanced Insulated Components could obtain significantly higher levels of thermal resistance than can be obtained by using Advanced Insulation Panels in composite with foam for Conventional $\mathrm{R} / \mathrm{F}$ doors.

(4) R/F doors constructed as atmospheric-pressure, gas-filled AICs could yield higher levels of thermal resistance than can be obtained using evacuated powder AIP/foam composite with either Conventional R/F or Polymer Shell R/F door assemblies.

(5) R/F doors constructed as evacuated powder AICs could yield the highest level of thermal resistance of all the designs considered.

\subsection{Polymer Technologies for Advanced Insulated Components}

An effort to improve overall levels of thermal resistance in $\mathrm{R} / \mathrm{F}$ cabinets and doors should consider further substitution of polymers for steel. The two primary attributes of polymers which can help improve thermal resistance levels are low thermal conductivity (compared to steel) and the capability to serve as gas and moisture barriers for modern advanced insulation technologies. Substituting polymers for metal can also provide other benefits including: freedom of design, consolidation of parts, reduction of weight, ease of recycling for fabrication scrap and postconsumer material, and consolidation of types of production processes. The thermal conductivity of a polymer is typically a factor of 200 lower than steel, so polymers should be considered for any steel $\mathrm{R} / \mathrm{F}$ components that act as thermal bridges, such as fasteners, stiffeners, brackets, hinges and outer-shells. Such use of polymers as "thermal breaks" is especially important for the door perimeter area. While reducing thermal bridging effects is important, the use of polymers in $\mathrm{R} / \mathrm{F}$ cabinet and door applications could offer considerably more value if they served as barrier envelopes for Advanced Insulated Components.

Advanced Insulated Components (AICs) use molded or formed, thin walled, hermetic polymer parts that incorporate barrier resins and serve as barrier envelopes for the advanced insulation technologies contained within. AICs for R/Fs could be entire doors, entire cabinets, inner liners, or portions of cabinets. Multilayer polymer technologies, such as coextrusion and lamination, could be used to incorporate layers of gas and moisture barrier materials. $\mathrm{R} / \mathrm{F}$ doors are constructed independent of cabinets and are therefore a logical R/F component for initial 
development of AICs for R/Fs. There is probably greater value in insulation thermal performance per thickness with doors compared to $\mathrm{R} / \mathrm{F}$ cabinets because of utility and volume derived from door sheives; R/F doors currently use thinner insulation than cabinets. AIC R/F dc ss could be fabricated in the near term by either coextrusion blowmolding or multilayer twin-sheet thermoforming. An AIC R/F inner liner may also be useful in an otherwise conventionally manufactured cabinet. Such an AIC inner liner would use a second thermoformed polymer part sealed to the inner liner forming a new cavity for advanced insulation.

A discussion of materials and technologies that may be useful for fabricating AICs for R/Fs must take into account environmental concerns, low cost manufacturing, and processes useful for producing multilayer gas-barrier functional parts. Polymer technologies are progressing rapidly with advances in diverse areas such as resin production, processing machinery, and part $/ \mathrm{mold}$ simulation capabilities. Many processes useful for fabricating appliance components have been, and will continue to be, developed as polymer technologies attempt to substitute for metal in a variety of applications, particularly automotive. We focus our discussion on thermoplastic polymers and processes because they are good candidates for recycling and are considered more environmentally friendly than other types of polymers, such as thermosets and composites.

Thermoplastics include basic groups such as: polyethylene (PE), polypropylene (PP), polystyrene (PS), and polyvinyl chloride (PVC) and a large number of higher order derivatives and specialty resins such as: acrylonitrile-butadiene-styrene (ABS), high-impact polystyrene (HIPS), and high density polyethylene (HDPE). Thermoplastic polymers can be ground and reused multiple times with minimal energy input and typically only minor degradation (from additional exposure to heat).

Multilayer polymer technologies can be used to impart barrier properties to polymer structures for AIC applications. While the majority of plastic parts are monolayer (comprised of a single resin or compound), technologies such as laminating and coextrusion can be used to combine two or more layers of separate polymers into a single structure. Multilayer technologies enable combining different polymers to obtain a structure with mechanical characteristics that could not be obtained with a single resin or compound. Coextrusion is used to produce multilayer films, sheets, and profiles for a variety of applications. Coextrusion can enable incorporating recycled plastics into middle layers, employing outside layers of special protective compounds (e.g. UV blocking, flame retarding), and employing gas-barrier resins in middle layers; all three of these uses may be applicable to AICs. Lamination can also be used to produce multilayer film and sheet. Multilayer barrier film could be laminated to monolayer sheet and subsequently formed into a functional part; this is one approach being considered to protect styrenic R/F liners from degradation by HCFC foam blowing agents. Very low gas-permeation rates can be obtained by incorporating a polymer gas-barrier material, such as ethylene vinyl alcohol (EVOH), into one or more layers of a multilayer structure. Low moisture transmission polymers, such as polyethylene and polypropylene, can also be incorporated into multilayer structures. While recycling monolayer thermoplastic material is usually straightforward, this is not always true for multilayer structures which tend to yield commingled scrap. However, multilayer structures composed of compatible materials are easily recycled; this has been demonstrated for $\mathrm{EVOH}$ in polypropylene based structures. Developing multilayer polymer structures for AICs will require selection of 
compatible materials and thorough testing to insure that fabrication scrap and post-consumer material is recyclable.

Thermoforming is a polymer processing technology that takes an initially uniform flat sheet and forms or draws the desired shape into it. Thermoforming is currently used to fabricate $\mathrm{R} / \mathrm{F}$ innerliners out of monolayer thermoplastic sheet (typically ABS or HIPS). Multilayer polymer sheet can be thermoformed in the same fashion as monolayer sheet. In thermoforming, the sheet is heated to soften the polymer and then drawn into a mold by vacuum and/or pressure. Forming difficult shapes can make use of a plug which is typically a male tool that helps drive the sheet into a female mold. Melt-phase pressure forming is similar to thermoforming but uses higher temperatures and can produce more complex shapes and use stiffer materials. A prototype polymer (polystyrene) external cabinet has been produced by melt-phase pressure forming [Remich 1992]. Twin-sheet thermoforming involves forming two separate sheets in one set of tooling and welding them together to produce a hollow part. Twin-sheet thermoforming is an excellent candidate for the production of AICs because inserts can be encased inside the part during the process and it can readily make use of multilayer sheet. A mold for twin-sheet production of a prototype $\mathrm{R} / \mathrm{F}$ door has been produced for developmental purposes [Plastics Technology 1992].

Blowmolding is another polymer processing technology for efficient production of thin-walled hollow parts. Blowmolding starts with polymer resins in pellet form, which are extruded in a cylindrical column of melt, called a parison. A portion of the parison is lowered into a bivalve mold. The mold is closed and pressurized gas is injected inside the parison, driving the polymer out to the surfaces of the mold. Multilayer coextrusion blowmolding is accomplished by using separate extruders for each individual polymer and feeding them into a crosshead. A crosshead takes the output of the different extruders and produces a parison with concentric layers of the individual polymers. A major automobile manufacturer intends to introduce a coextruded blowmolded vehicle fuel tank in 1995; this tank will include EVOH and recycled HDPE in a sixlayer structure [Foster 1992].

Injection molding processes are well developed and widely used to fabricate plastic parts. Injection molding is used for most solid parts; however thin-walled hollow parts can also be produced, frequently with gas-assist technologies. Parts are fabricated by injecting extruded polymer into a mold at high pressure. Large parts require equipment with a great deal of clamping force. A variety of new processes and refinements for injection molding are emerging that can improve the quality of molded parts and/or reduce the clamping force requirements. Coextrusion injection molding is a newly emerging technology but may ultimately be useful for multilayer polymer barrier parts in the future.

We have not attempted to estimate costs for polymer barrier AICs because considerable additional design and manufacturing engineering would be required for a meaningful economic analysis. In a separate application, more stringent requirements for vehicle emissions of hydrocarbons are prompting development of high barrier polymer vehicle fuel tanks. Some of the approaches for fuel tanks would use materials and processes also useful for AIC barrier envelopes and may ultimately yield cost information relevant to AICs [Schut 1992]. It is clear that 
Advanced $\mathrm{R} / \mathrm{Fs}$ would require a substantial engineering project on product design and manufacturing tooling. Incorporating AICs with functional gas-barrier components in R/F cabinets and doors would require major investments in tooling and new types of polymer processing equipment to supplement (or replace) existing equipment currently used to fabricate sheet metal, foam core components. However, a R/F manufacturer that wanted to pursue Advanced R/Fs could expect considerable assistance from various sectors of the plastics industry.

The logistics of locating an insert consisting of an advanced insulation filler material within the volume of an AIC will probably require that the outer surface be comprised of two bivalve parts. Filler material inserts would be located between the parts and the parts would subsequently be sealed. It would be worth investigating techniques to "blow in" a soft-vacuum filler material or a loose-fill reflective baffle to enable the use of a one part outer surface; however, density and geometry requirements will likely inhibit such an approach. This situation favors twin-sheet thermoforming over blowmolding because with twin-sheet thermoforming the tooling can allow encapsulating an insert within the component. In the case of a blowmolding process, parts would likely have to be split open and subsequently sealed. Consistently obtaining well-sealed, large, complex parts would be very challenging. However, because plastics allow flexibility in design, flanges, surfaces, and throughputs could be incorporated into the two parts such that they mate and seal well. It is not overly difficult to join hermetically two plastic parts that mate well. Possible techniques include solvent, thermal, ultrasonic, and laser welding and the use of adhesives. The atmosphere within the parts could be modified (evacuation or gas-fill) after the main sealing process with the use of a vacuum chamber.

Structural, stiffness and thermal stability issues would be very important for polymer barrier AICs in $\mathrm{R} / \mathrm{F}$ applications. Foam provides considerable stiffness in Conventional $\mathrm{R} / \mathrm{Fs}$, and eliminating it would create challenging design problems. With evacuated insulation technologies, filler material (powder or aerogel) would support the assembly under nearly atmospheric pressure and would generally stiffen the assembly. With gas-fill technologies, neither atmospheric pressure nor the baffle would lend much stiffness to the assembly. Stiffness for a gas-filled AIC would have to be derived from carefully designed outer surface parts and polymer inserts such as rigid foam or extrusions. (Test run 13 of the modeling exercise presented above is a gas-filled AIC with a rigid polymer foam perimeter and center section.) An AIC in an Advanced R/F would be exposed to cold temperatures on one side and ambient temperatures on the other which could cause problems because of differential thermal contraction and expansion.

Using EVOH in a multilayer polymer structure can result in gas transmission rates of approximately $0.08 \mathrm{cc} / \mathrm{m}^{2} \cdot 24 \mathrm{hr} \cdot$ atm for oxygen with an EVOH barrier material ( $38 \%$ ethylene) thickness of 5.0 mils $(125 \mathrm{~m})$ [EVALCA \#110]. This level of gas-barrier can be sufficient to maintain performances of gas-filled, and some types of evacuated advanced insulation technologies for the life of the appliance. The gas-barrier can be increased with thicker layers and higher performance grades of EVOH. Other barrier polymers and barrier coatings may also be applicable, including polyvinyl alcohol (PVOH), acrylonitrile copolymer, Polyvinylidene chloride (PVdC), and vacuum deposited metal and oxide coatings. The multilayer structures must also be designed for very low rates of moisture permeation. Much prototype development and testing will be necessary to verify long-term barrier performance and reliability. 


\subsection{Summary and Conclusions}

A number of issues with current and long range implications for Refrigerator/Freezer (R/F) appliances make a strong argument for the need to redesign residential R/Fs. Near term issues include the elimination of CFCs and requirements for increased energy efficiency; long term issues include continued demand for increases in energy efficiency and an emphasis on recycling. Conventional $\mathrm{R} / \mathrm{F}$ design and manufacture makes substantial increases in thermal resistance (without an increase insulation thickness) difficult and the adhesive foam core makes recycling of expended units impractical. Advanced insulation technologies, such as gas-filled and evacuated powder, offer the potential for improvements in thermal resistance and energy efficiency and do not require CFCs or completely impermeable (i.e. steel) barrier envelopes. Advanced insulation technologies in the form of Advanced Insulation Panels (AIPs), are currently being developed for use in composite with foam for otherwise conventional R/Fs; this technique, however, is only marginally effective because of thermal bridging effects resulting from the steel outer shell materials and spatial heat flows due to regions of lower performance foam. The thickness of AIPs is also limited by the requirements for foaming. This reports suggests another possible use of advanced insulation technologies is to incorporate them directly into the product's design with the use of hermetic, gas-barrier, multilayer thermoplastic functional parts; we refer to such parts as Advanced Insulated Components (AICs). Using AICs as basic elements in R/F cabinet and door applications yields what we refer to as Advanced R/Fs. Advanced R/Fs are a long-range design option for using advanced insulations to their maximum potential. For example, an AIC R/F door would primarily consist of an outer polymer shell sealed to an inner polymer liner creating a single hermetic barrier envelope which encapsulates an advanced insulation filler material. A preliminary three-dimensional thermal modeling exercise of a simple flat assembly showed that performance levels for AICs can be significantly higher than AIP/foam composite insulated assemblies. Additional modeling and experimental verification is warranted for an accurate prediction of the performances attainable with Advanced R/Fs.

We conclude:

1. Advanced Insulated Components could be mass produced with existing polymer technologies.

2. Thermal performance levels for Advanced Insulated Components can be significantly greater than that possible with conventional $\mathrm{R} / \mathrm{F}$ assemblies insulated with Advanced Insulation Panel/Foam composites of the same thickness.

3. A considerable amount of development is required and warranted to assess the energy efficiency improvements, economics, manufacturing, and reliability of AICs for R/F applications. 


\section{References}

[Childs 1992] Childs, K. 1992. Personal Communication. Oak Ridge National Laboratory, Oak Ridge, $\mathrm{TN}$.

[EVALCA \#110] Technical Bulletin No. 110. Gas Barrier Properties of EVAL Resins. EVAL Company of America, Lisle II.

[Foster 1992] Foster, R. 1992. Personal Communication. EVAL Company of America, Lisle IL.

[Griffith 1991] Griffith, B.T., D. Arasteh, and S. Selkowitz. 1991. Gas-filled panel highperformance thermal insulation. Insulation Materials: Testing and Applications, 2d vol., Graves/Wysocki, eds. Philadelphia, American Society of Testing and Materials.

[Hunt 1991] Hunt, A.J., C.A. Jantzen, and W. Cao. 1991. Aerogel - a high performance insulating material at 0.1 bar. Insulation Materials: Testing and Applications, $2 \mathrm{~d}$ vol., Graves/Wysocki, eds. Philadelphia, American Society of Testing and Materials.

[Kollie 1991] Kollie, T.G., D.L. McElroy, H. A. Fine, K.W. Childs, R. S. Graves, and F. J. Weaver. 1991. A review of vacuum insulation research and development in the building materials group of the Oak Ridge National Laboratory. ORNL/TM-11703. Oak Ridge National Laboratory, Oak Ridge, TN.

[Leaversuch 1990] Leaversuch, R. 1990. Total redesign of refrigerators now is inevitable. Modern Plastics, October 1990. McGraw-Hill.

[Plastics Technology 1992] Processors' Page. 1992. A better bond in twin-sheet forming. Plastics Technology, June 1992. Bill Communications.

[Remich 1992] Remich, N. 1992. 'Green Frost': a recyclable refrigerator. Appliance Manufacturer, April 1992. Business News Publishing Co.

[Schut 1992] Schut, J.H. 1992. Auto gas tanks: the great barrier grief. Plastics Technology, May 1992. Bill Communications.

\section{Acknowledgments}

This work was funded by the U.S. Environmental Protection Agency, Office of Research and Development under Inter-Agency Agreement No. DW89935253-01-0. Additional funding was provided by Southern California Edison through the California Institute for Energy Efficiency (CIEE), a research unit of the University of California, under Contract No. EXPC-92-02. Publication of research results does not imply CIEE endorsement of or agreement with these findings, nor that of any CIEE sponsor. Additional funding was provided by the Assistant 
Secretary for Conservation and Renewable Energy, Office of Building Technologies, Building Systems and Materials Division of the U.S. Department of Energy under Contract No. DEACO3-76SF00098.

The authors wish to thank Tom Kollie and Ken Childs of Oak Ridge National Laboratory for performing the HEATING-7 modeling calculations presented in this report. The authors also wish to thank their colleague Ian Sundly for his assistance in preparing this report. 

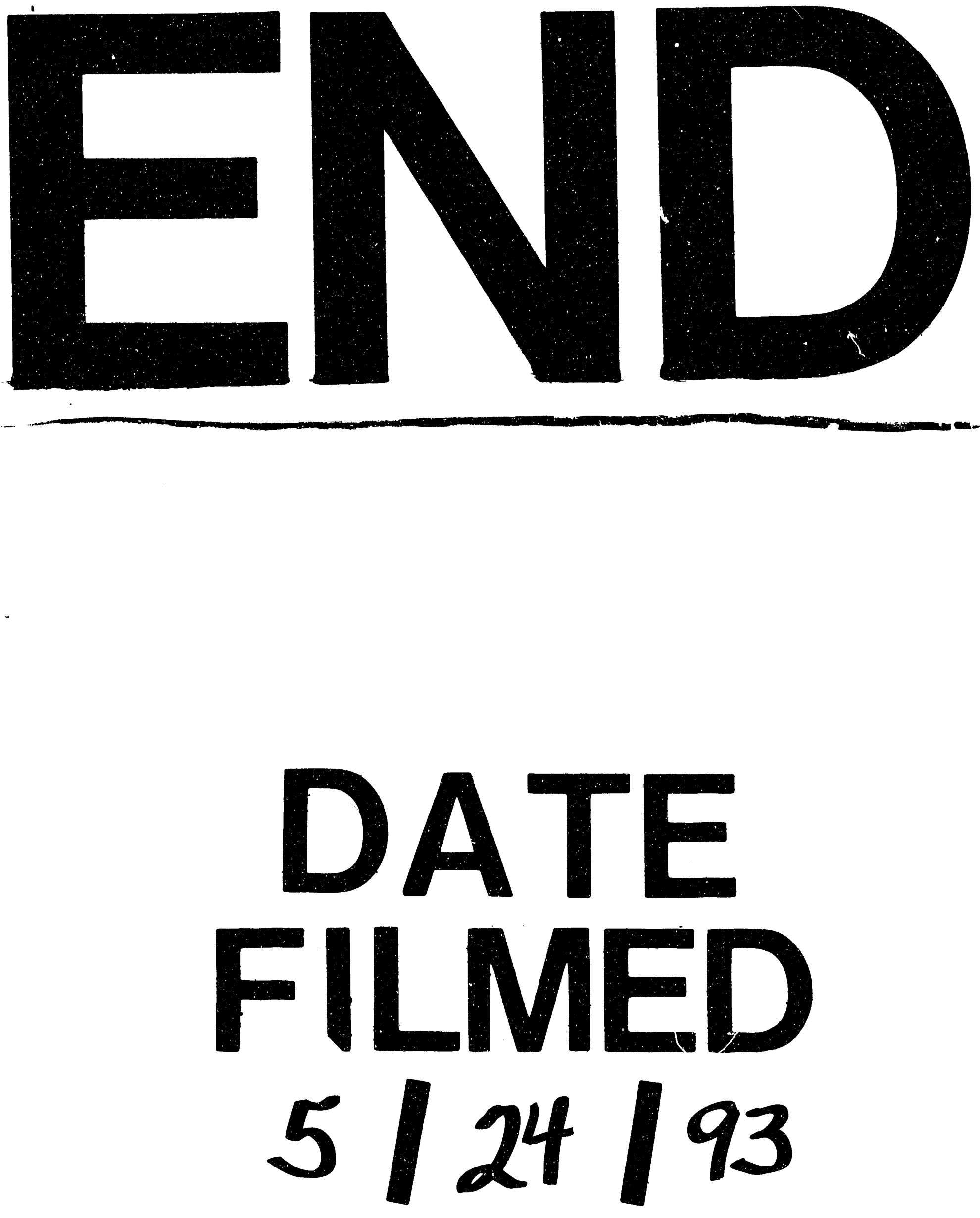
